\title{
Antifungal Efficacy of Amphotericin B in Candida Albicans Endocarditis Therapy: Systematic Review
}

\author{
Lucas Soares Bezerra1,2, MD; Janielli Assis da Silva', MD; Marcelo Antônio Oliveira Santos-Veloso², MD; Sandro \\ Gonçalves de Lima ${ }^{1,3}$, MD, PhD; Ândrea Virgínia Chaves-Markman ${ }^{1,2,3}$, MD, MSc; Moacir Batista Jucá1 , MD, PhD
}

\begin{abstract}
Introduction: Although it is the most common agent among the fungal causes of endocarditis, Candida albicans endocarditis is rare.

Objective: To evaluate the efficacy of amphotericin B in the treatment of $C$. albicans endocarditis beyond a systematic review.

Data search: Articles in English, Spanish and Portuguese, conducted in the following databases: MEDLINE, LILACS, IBECS and SCiELO, in humans and published in the last 25 years.

Study selection: Observational studies, clinical trials, and case series providing data on the amphotericin $B$ use in patients with a $C$. albicans endocarditis diagnosis without age limitations.

Data synthesis: From the initial search $(n=79), 25$ articles were
\end{abstract}

fully evaluated, of which 19 were excluded for meeting one or more exclusion criteria, remaining five articles (two observational studies and three case series). Patients using amphotericin B demonstrated improvement in survival rates, and its main use was in association with the surgical method as well as with caspofungin association.

Conclusion: Literature lacks evidence to conclude about efficacy and safety of amphotericin B in the treatment of fungal endocarditis. Randomized clinical trials are necessary to provide better evidence on the subject.

Keywords: Amphotericin B. Antifungal Agents. Candida Albicans. Endocarditis, Mycoses, Survival Rate.

\begin{tabular}{ll}
\hline Abbreviations, acronyms \& symbols \\
\hline AHRQ & $=$ Agency for Healthcare Research and Quality \\
AMB & $=$ Amphotericin B \\
FE & $=$ Fungal endocarditis \\
MIC & $=$ Minimum inhibitory concentration \\
NIH & $=$ National Institutes of Health
\end{tabular}

\section{INTRODUCTION}

Fungal endocarditis (FE) is a rare disease, occurring mainly in patients with predisposing host conditions ${ }^{[1]}$, but with a propensity to be severe. Candida species are the most usual etiological agents, with C. albicans being the most common among them ${ }^{[2-4]}$. Infective endocarditis caused by Candida spp. is associated with a high mortality rate, between $30 \%$ and $80 \%[5]$.

Besides the severity of this opportunistic infection, its diagnosis is difficult and also delayed, due to the low suspicion

${ }^{1}$ Centro Universitário Mauricio de Nassau, Recife, Brazil.

2Pós-graduação em Inovação Terapêutica (PPGIT), Centro de Biociências, Universidade Federal de Pernambuco, Recife, Brazil.

${ }^{3}$ Departamento de Cardiologia, Hospital das Clínicas da Universidade Federal de Pernambuco (HC/UFPE), Recife, Brazil.

This study was carried out at the Pós-graduação em Inovação Terapêutica (PPGIT), Centro de Biociências, Universidade Federal de Pernambuco, Recife, Brazil. of the physician and the poor sensitivity of blood cultures ${ }^{[2]}$. Determining patients at high risk of FE is not simple considering the lack of information in medical literature about the clinical features and therapy ${ }^{[1]}$. Predisposing conditions are previous surgery, intravenous drug addiction, underlying heart disease, indwelling foreign bodies (catheters, prosthetic valves or pacemakers), immunosuppression, post-transplantation, postchemotherapy, prolonged use of broad-spectrum antibiotics, $\mathrm{HIV}$, and chronic underlying diseases as diabetes mellitus ${ }^{[1,6-8]}$.

The first-line drug for C. albicans endocarditis is amphotericin $B(A M B)$, often followed by fluconazole because of frequent relapses ${ }^{[6]}$. AMB deoxycholate therapy acts by binding to the ergosterol of fungal membranes, creating channels through which vital molecules leak from the cells, leading to cellular death ${ }^{[9]}$. However, C. albicans is capable of biofilm formation, which serves as a barrier to block penetration of antimicrobial agents and confers resistance to several antifungals, which can decrease the activity of antifungals that target ergosterol such as amphotericin ${ }^{[10,11]}$.

Correspondence Address:

Lucas Soares Bezerra

(iD) https://orcid.org/0000-0001-6880-0205

Centro Universitário Mauricio de Nassau

Rua Jonathas de Vasconcelos, 316, Boa Viagem, Recife, PE, Brazil

Zip code: 51021-140

E-mail: lucassbezerra@gmail.com

Article received on April 16 $16^{\text {th }}, 2019$ Article accepted on October $14^{\text {th }}, 2019$. 
Surgical intervention is considered the gold standard in addition to pharmacological therapy ${ }^{[12]}$, but in some cases a good response has been achieved only with drug therapy, especially $A M B^{[9,13]}$. These cases include patients with minor vegetations found and high risk of perioperative death, whose pharmacological therapy should be first-line treatment ${ }^{[14,15]}$. Some studies demonstrate that surgical approach is not associated with increased survival rate compared to antifungal monotherapy with $\mathrm{AMB}^{[6,14]}$. Furthermore, among patients without surgical intervention, the history of relapses was not observed ${ }^{[15]}$. Therefore, antifungal monotherapy with AMB may be considered, especially in critically ill patients in whom surgery is not a viable option ${ }^{[13]}$.

Although some international guidelines recommend $A M B$ as first-line drug in the treatment of FE, evidence regarding this topic is scarce and controversial. To our knowledge, this is the first systematic review on this subject.

\section{Objective}

To evaluate the antifungal efficacy of amphotericin B in the treatment of $C$. albicans endocarditis; elucidate the drug efficacy, including its use as a complement or substitute for the surgical approach.

\section{METHODS}

\section{Protocol and Registration}

The methods used in this work followed the systematic review process derived from the PRISMA statement ${ }^{[16]}$. Details of the study protocol are registered on PROSPERO under registration number CRD42019106445.

\section{Eligibility Criteria}

\section{Types of studies}

This paper covered observational studies, clinical trials, and case series published in the last 25 years in English, Spanish or Portuguese. Considering that this study aims to evaluate amphotericin B effects only in humans, experimental studies were not included.

\section{Types of participants}

Patients with clinical and mycological diagnosis of C. albicans endocarditis. No age restrictions were applied.

\section{Types of interventions}

The intervention consisted of the use of $\mathrm{AMB}$ alone or in association compared to placebo, another antifungal therapy and/or surgical treatment for FE.

\section{Types of outcome measures}

We considered as outcome measures: all-cause death, length of treatment, mycological cure (defined as negative blood culture after treatment), relapse of infection. In addition, the serum minimum inhibitory concentration (MIC) was evaluated as a variable.

\section{Information Sources}

The following databases were consulted: MEDLINE, LILACS, IBECS and SciELO. Publications in English, Spanish or Portuguese were accessed. We considered only studies performed in humans and published in the last 25 years. The last search was run on January 2, 2019. The full electronic search strategy is available in Appendix 1.

\section{Study Selection}

The eligibility assessment was executed independently and unblended standardized by two authors. Disagreements were resolved by a third author.

\section{Data Collection Process}

Data extraction was made using a standard form. The form consisted of a pilot test in randomly selected included studies and adjusted accordingly. Disagreements were resolved by a third author.

\section{Data Items}

The following data was extracted from full-text articles: (1) participant characteristics (including age, sex, number, associated comorbidities, and diagnostic method), (2) study design (including design, follow-up period, and type of intervention), and (3) outcomes (including mortality and survival rate).

\section{Risk of Bias in Individual Studies}

To ascertain the validity and risk of bias, the reviewers determined the adequacy of data extraction, the blinding status of the study, the loss of follow-up and homogeneity of the examined samples. To help assess the quality of the studies, two different scales were used, according to the study design.

The quality of observational studies was assessed by the Agency for Healthcare Research and Quality (AHRQ) criteria for observational studies ${ }^{[17]}$. Acceptable quality was defined as a score of at least 50 points out of 100 . The quality assessment is described in Table 1.

The quality of the case series was assessed by the National Heart, Lung and Blood Institute (NIH) scale. An acceptable quality was defined as a minimum score of five yeses out of nine criteria, as shown in Table 2.

\section{Summary Measures}

The primary measure of treatment efficacy was the relative risk of declining mortality or increased survival rates.

\section{Additional Analysis}

The sensitivity analysis was evaluated according to the quality components pointed in the AHRQ and $\mathrm{NIH}$ scales.

\section{RESULTS}

From the initial search ( $n=79), 25$ articles were fully reviewed, as demonstrated in Figure 1. From those, 19 were excluded: seven 
Table 1. Quality assessment for observational studies according to the AHRQ criteria.

\begin{tabular}{|c|c|c|c|}
\hline Criteria & Weighted score points & Badiee et al. ${ }^{[18]}$, Iran, 2014 & Melgar et al. ${ }^{[19]}$, USA, 1997 \\
\hline Study question & $(0-2)$ & 2 & 2 \\
\hline Study population & $(0-8)$ & 8 & 8 \\
\hline Comparability of subjects & $(0-22)$ & 9 & 6 \\
\hline Exposure or intervention & $(0-11)$ & 11 & 8 \\
\hline Outcome measure & $(0-20)$ & 20 & 15 \\
\hline Statistical analysis & $(0-19)$ & 12 & 17 \\
\hline Results & $(0-8)$ & 8 & 5 \\
\hline Discussion & $(0-5)$ & 5 & 5 \\
\hline Funding & $(0-5)$ & 5 & 0 \\
\hline TOTAL & $(0-100)$ & 80 & 66 \\
\hline
\end{tabular}

Table 2. Quality assessment for case series according to the NIH criteria.

\begin{tabular}{|c|c|c|c|}
\hline \multirow{2}{*}{ Criteria } & $\begin{array}{l}\text { Stripeli et al. }{ }^{[13]} \text {, } \\
\text { Grécia, } 2008\end{array}$ & $\begin{array}{c}\text { Karatza et al. }{ }^{[21]}, \\
\text { Grécia, } 2008\end{array}$ & $\begin{array}{c}\text { Flanagan et al. }^{[20]}, \\
\text { Inglaterra, } 1997\end{array}$ \\
\hline & Yes/No/Other ${ }^{a}$ & Yes/No/Other ${ }^{a}$ & Yes/No/Other ${ }^{a}$ \\
\hline $\begin{array}{l}\text { 1. Was the study question or objective clearly } \\
\text { stated? }\end{array}$ & Yes & Yes & Yes \\
\hline $\begin{array}{l}\text { 2. Was the study population clearly and } \\
\text { completely described, including a case } \\
\text { definition? }\end{array}$ & Yes & Yes & Yes \\
\hline 3. Were the cases consecutive? & NR & NR & NR \\
\hline 4. Were the subjects comparable? & Yes & Yes & No \\
\hline 5. Was the intervention clearly described? & Yes & Yes & Yes \\
\hline $\begin{array}{l}\text { 6. Were the outcome measures clearly defined, } \\
\text { valid, reliable, and consistently implemented } \\
\text { across all study participants? }\end{array}$ & Yes & Yes & Yes \\
\hline 7. Was the follow-up duration adequate? & Yes & No & NA \\
\hline 8. Were the statistical methods well described? & NA & NA & NA \\
\hline 9. Were the results well described? & Yes & Yes & Yes \\
\hline
\end{tabular}

a Other: $C D=$ cannot determine; $N A=$ not applicable; $N R=$ not reported

because of study design, six because the publication date was over 25 years, six because evaluated therapy did not include AMB, and one because of language restriction (Chinese). There were five articles that met the selection criteria: two observational studies and three case series. The methodological assessment of the studies is shown in Table 3.

In a cross-sectional study developed by Badiee et al. ${ }^{[18]}$, out of 31 patients with suspected infective endocarditis, 11 had fungal etiology (Aspergillus spp. and C. albicans). Out of the 11, only two were by C. albicans, both intravenous drug users and with fever as a common symptom. They were surgically treated in association with AMB for a minimum of 6 weeks. After treatment, one of the two patients remained with positive blood culture, and both presented positive histopathology. There was no report of death, and after the 12-month follow-up period, they were clinically well. 


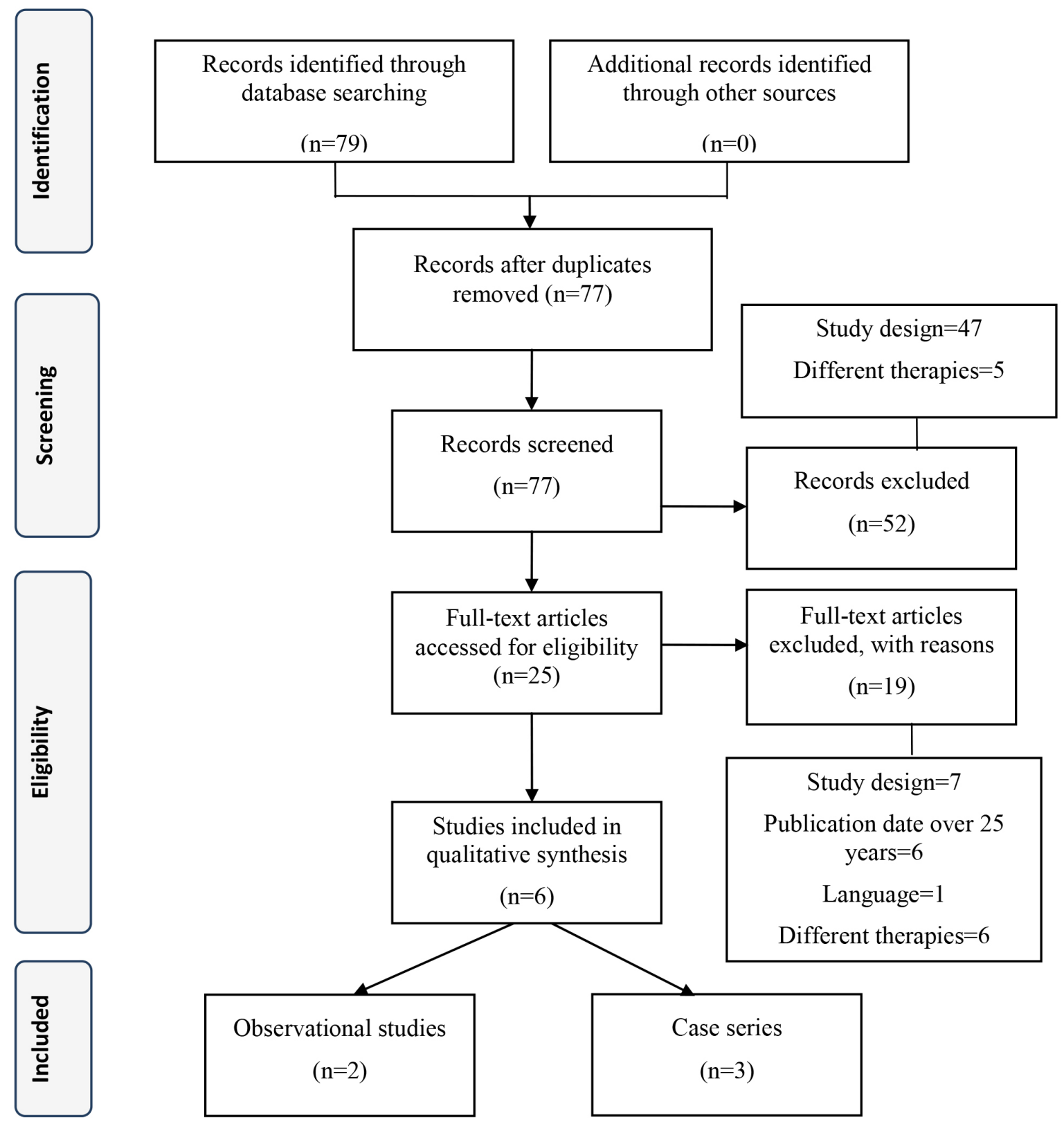

Fig. 1 - PRISMA flow diagram of studies.

Analyzing the mean minimum inhibitory concentration (MIC) in both C. albicans infected patients, AMB level $(0.375 \mu$ / $\mathrm{mL})$ was lower than voriconazole $(0.3825 \mu / \mathrm{mL})$, itraconazole $(0.75 \mu / \mathrm{mL})$, ketoconazole $(1.25 \mu / \mathrm{mL})$ and fluconazole $(24 \mu$ / $\mathrm{mL}$ ), demonstrating a higher sensitivity profile of the agent to AMB treatment compared to these antifungals, but was higher than that of posacoazole $(0.079 \mu / \mathrm{mL})$ and caspofungin $(0.024$ $\mu / m L)$.

In another study, nine adults with prosthetic valve endocarditis seen between 1985 and 1996 were infected by C. albicans $^{[19]}$. The medical records were evaluated, with emphasis on comorbidities and associated risk factors, microbiological information, treatment modalities and clinical features. The therapy of choice was the association between $A M B$ and valve replacement surgery. They reported only one death, and it was due to surgical complication after a laparotomy and resection of the superior mesenteric artery, portion of the small intestine and spleen after acute abdomen secondary to an aneurysm.

Out of the three patients reported by Flanagan et al. ${ }^{[20]}$, two had C. albicans endocarditis. Endocarditis was evaluated by 
Table 3. Summary of included studies evaluating the antifungal efficacy of AMB in the treatment of C. albicans endocarditis.

\begin{tabular}{|c|c|c|c|c|c|c|c|c|c|c|}
\hline Source & $\begin{array}{c}\text { No. of } \\
\text { patients }\end{array}$ & $\begin{array}{c}\text { Age } \\
\text { range }\end{array}$ & $\begin{array}{l}\text { Study } \\
\text { design }\end{array}$ & Inclusion criteria & $\begin{array}{l}\text { Follow- } \\
\text { up } \\
\text { (months) }\end{array}$ & $\begin{array}{l}\text { Death } \\
\text { rate } \\
(\%)\end{array}$ & $\begin{array}{l}\text { Median } \\
\text { blood } \\
\text { sample } \\
\text { MIC }(\mu / \\
\mathrm{mL})\end{array}$ & $\begin{array}{l}\text { Median } \\
\text { time to start } \\
\text { antifungal } \\
\text { treatment } \\
\text { (days) }\end{array}$ & $\begin{array}{l}\text { Negative } \\
\text { blood } \\
\text { culture after } \\
\text { treatment } \\
(\%) / \text { time for } \\
\text { negative } \\
\text { result (days) } \\
\end{array}$ & $\begin{array}{c}\text { Relapse } \\
(\%) / \\
\text { median } \\
\text { time for } \\
\text { relapse } \\
\text { (months) }\end{array}$ \\
\hline \multicolumn{11}{|c|}{ Studies with adults } \\
\hline $\begin{array}{c}\text { Badiee et } \\
\text { al. }{ }^{[18]}, 2014\end{array}$ & $\begin{array}{l}2 \text { (from } \\
11)^{\mathrm{a}}\end{array}$ & $\begin{array}{l}21-31 \\
\text { years }\end{array}$ & $\begin{array}{c}\text { Cross- } \\
\text { sectional }\end{array}$ & $\begin{array}{c}\text { Infectious } \\
\text { endocarditis patients } \\
\text { after non-responsive } \\
\text { antibacterial } \\
\text { treatment, } \\
\text { positive culture } \\
\text { and transthoracic } \\
\text { echocardiogram }\end{array}$ & 12 & $0(n=0)$ & 0.375 & NR & $50 / \mathrm{NR}$ & NR \\
\hline $\begin{array}{c}\text { Melgar et } \\
\text { al. }{ }^{[19]}, 1997\end{array}$ & $\begin{array}{l}9 \text { (from }^{16)^{\mathrm{a}}}\end{array}$ & $\begin{array}{l}27-71 \\
\text { years }\end{array}$ & $\begin{array}{l}\text { Case- } \\
\text { control }\end{array}$ & $\begin{array}{l}\text { Diagnosis of } \\
\text { FE according } \\
\text { to histological } \\
\text { evidence, plus at } \\
\text { least one positive } \\
\text { culture (same } \\
\text { fungus from the } \\
\text { histological tissue) }\end{array}$ & 54 & $11(n=1)$ & NR & NR & NR & $11 / 28$ \\
\hline $\begin{array}{l}\text { Flanagan et } \\
\text { al. }{ }^{[20]}, 1997\end{array}$ & $\begin{array}{c}2 \text { (from } \\
3)^{\mathrm{a}}\end{array}$ & $\begin{array}{l}74-76 \\
\text { years }\end{array}$ & Case series & $\begin{array}{l}\text { Blood culture } \\
\text { confirmed by post- } \\
\text { mortem histology. }\end{array}$ & NR & $\begin{array}{c}100 \\
(n=2)\end{array}$ & 0.275 & 6 & NR & NR \\
\hline \multicolumn{11}{|c|}{ Studies with infants } \\
\hline $\begin{array}{l}\text { Karatza et } \\
\text { al. }{ }^{[21]}, 2008\end{array}$ & 2 & $\begin{array}{c}<1 \\
\text { month }\end{array}$ & Case series & $\begin{array}{c}\text { Premature newborns } \\
\text { diagnosed by clinical } \\
\text { features, positive } \\
\text { blood culture } \\
\text { and transthoracic } \\
\text { echocardiogram }\end{array}$ & NR & $0(n=0)$ & 0.0195 & 19 & $50 / 3$ & NR \\
\hline $\begin{array}{l}\text { Stripeli F et } \\
\text { al. }{ }^{[13]}, 2007\end{array}$ & 2 & $\begin{array}{c}2-3 \\
\text { months }\end{array}$ & Case series & $\begin{array}{l}\text { Children diagnosed } \\
\text { by clinical features, } \\
\text { positive blood } \\
\text { culture and } \\
\text { echocardiogram }\end{array}$ & 54 & $0(n=0)$ & NR & 7 & $50 / 4$ & O/NA \\
\hline
\end{tabular}

$\mathrm{AMB}=$ amphotericin $\mathrm{B} ; \mathrm{EA}=$ etiological agent; $\mathrm{FE}=$ fungal endocarditis; L-AMB=liposomal amphotericin $\mathrm{B} ; \mathrm{MIC}=$ minimum inhibitory concentration; $\mathrm{NA}=$ not applicable; $N R=$ not reported

aThe number in parenthesis represents the total sample of the study, which included other fungal species besides C. albicans.

echocardiography and C. albicans was isolated by three peripheral blood samples. The first case progressed with operative site necrosis and osteomyelitis involving tibia and fibula, submitted to lower limb amputation surgery, and the patient died. Initially, the AMB MIC was 0.3 versus 1.0 for fluconazole, suggesting a higher sensitivity to AMB. In the second case, the patient started treatment with fluconazole for four weeks, then starting oral $A M B$ in combination with oral flucytosine associated with amphotericin B in colloidal dispersion (amphocil), replacing fluconazole. The patient died two weeks later due to heart failure. Blood MIC was $<0.25$ for AMB and 1.0 for fluconazole.
Two cases of infants ( 2 and 3 months of age) with endocarditis after congenital heart surgery were presented by Stripeli et al. ${ }^{[13]}$. Both patients received AMB treatment without surgical intervention. Endocarditis was evaluated by echocardiogram and C. albicans was isolated through a blood sample. One patient started the treatment with AMB (1 mg/kg/day). Fluconazole $(8$ $\mathrm{mg} / \mathrm{kg} /$ day, then $13 \mathrm{mg} / \mathrm{kg} /$ day) was included on the $10^{\text {th }}$ day, using this combination for 14 days. After that, AMB was replaced by liposomal amphotericin B (L-AMB) $(5 \mathrm{mg} / \mathrm{kg} /$ day). With the new medication, blood collection was normal after 4 days, and vegetation in the tricuspid valve disappeared after 28 days. The 
other patient received L-AMB (5 mg/kg/day) for 7 weeks, with no side effects detected, and subsequent use of fluconazole (5 mg/ $\mathrm{kg} /$ day) for six months, showing clinical improvement.

Karatza et al. ${ }^{[21]}$ presented other two neonatal pediatric patients born with very low birth weight $(<1500 \mathrm{~g})$. The first was female, born at 28 weeks gestation and 1,270 g; and the second, male, 29 weeks and 1,280 g. Endocarditis was evaluated by echocardiogram and C. albicans was isolated by a blood sample. Clinical improvement was measured by the presence or absence of candidemia through a blood culture. In the first case, C. albicans was isolated in blood culture on day 20 , and ampicillin and gentamicin were replaced by L-AMB $(5 \mathrm{mg} / \mathrm{kg} /$ day $)$, and after six days with persistence of candidemia, caspofungin (1 $\mathrm{mg} / \mathrm{kg} /$ day and after two days $2 \mathrm{mg} / \mathrm{kg} /$ day) was started. On day 40 , with persistence of candidemia, caspofungin was replaced by fluconazole $(6 \mathrm{mg} / \mathrm{kg} /$ day), with improvement in blood culture 72 hours after new therapy. In the second case, L-AMB was started after blood culture results on day 18 , and on day 23 was associated with caspofungin. On day 47 , caspofungin was replaced by fluconazole, with improvement five days after the start of new therapy. Both patients used the same doses.

\section{DISCUSSION}

Fungal endocarditis represents a low percentage of total endocarditis. However, increases in the number of cases have been described. This is a result of the increase of immunocompromised patients, valve prosthesis surgery, pacemakers implantation, diffusion of central lines and broadspectrum antibiotic therapy ${ }^{[7,22,23]}$. Badiee et al. ${ }^{[18]}$ described the incidence of infective endocarditis after surgical procedures.

Despite being an uncommon condition, FE has a mortality rate $>50 \%$, according to the 2015 ESC Guidelines for the management of infective endocarditis ${ }^{[24]}$. In our review, the average mortality rate found in five studies was around $18 \%$. The incidence of FE now comprises 1-10\% of all etiological agents isolated in patients with infective endocarditis ${ }^{[18]}$. Within this subgroup of endocarditis, $50-70 \%$ are due to Candida species, with $C$. albicans being the most common ${ }^{[4,22]}$. Candida endocarditis is, therefore, a rare entity that requires special attention due of its high morbidity and mortality ${ }^{[22]}$.

Endocarditis should be suspected in cases when blood cultures are persistently positive, when a patient with candidemia has persistent fever despite appropriate treatment, or when a new heart murmur, heart failure, or embolic phenomenon occur in the setting of candidemia ${ }^{[25,26]}$. Beyond that, clinical features are very important: one of the studies analyzed in our systematic review showed that a patient's death occurred after treatment discontinuation based on a transthoracic echocardiogram negative for endocarditis ${ }^{[20]}$.

AMB may not effectively penetrate fungal vegetations. The use of a concomitant second agent, such as flucytosine, is recommended, since the association of drugs may potentiate the resolution of fungal vegetations. AMB plus fluconazole have previously been reported to be effective in both native and prosthetic valve Candida endocarditis ${ }^{[21]}$.

Medical therapy of Candida endocarditis has occasionally been curative, but the optimal therapy for both native and prosthetic valve endocarditis in adults is a combination of valve replacement and a long course of antifungal therapy, based on different studies. Because Candida endocarditis has a propensity to relapse months to years later, follow-up should be maintained for several years after treatment ${ }^{[27]}$.

The 2015 Infectious Diseases Society of America guidelines for the management of Candida endocarditis state that native valve and prosthetic valve infections should be managed with surgical replacement of the infected valve $e^{[27,28]}$. The recommended antifungal therapy for initial therapy is lipid formulation of AMB, 3-5 mg/kg daily, with or without flucytosine, $25 \mathrm{mg} / \mathrm{kg} 4$ times daily, or high-dose echinocandin. In pacemaker infections, implantable cardiac defibrillator and ventricular assist device, the entire device should be removed as soon as possible, considering the risk of causing embolism ${ }^{[1]}$.

According to Noguchi et al. ${ }^{[14]}$, fungal endocarditis is considered an absolute indication for surgery, but is not always possible to remove the infected valve. The high risk of intraoperative mortality ruled out the patient as a surgical candidate. Furthermore, in their study, because the patient suffered clinically insignificant embolic complication and had no vegetation or paravalvular leakage, they did not insist on removing the valve ${ }^{[29,30]}$. Lejko-Zupanc et al. ${ }^{[12]}$ defend that in selected cases, particularly those with few complications or minor vegetation, clinical treatment should be attempted first.

Supporting this recommendation, Rivoisy et al. ${ }^{[15]}$ showed that their multivariate analysis indicated two factors independently associated with lower odds of surgery success: older age and presentation with cardiac failure. In one third of cases, the decision not to operate was motivated by the estimated low severity of the endocarditis, which indicates that surgeons do not systematically follow current guidelines. Importantly, the sixmonth mortality outcomes in patients not operated were similar to those in patients who underwent surgery ${ }^{[15]}$.

Lefort et al. ${ }^{[31]}$ showed that among 33 cases, the mortality rate was similar regardless of whether surgery was performed or not and any difference was found in prognosis according to the management of Candida endocarditis: medical therapy alone versus combined with surgery. However, their results suggest that early cardiac surgery during CE should always be attempted, and only patients with very poor medical status might not be operated. For the latter patients, definitive antifungal therapy may be considered.

\section{Limitations}

The data about antifungal therapy in Candida FE were very heterogeneous considering differences between drug doses and combination, follow-up period, and patient age. Considering the rarity of $C$. albicans endocarditis, the number of studies was low, as expected.

Our results were based on observational studies comprised by a small sample. To date, no randomized clinical trial evaluated the efficacy and safety of AMB in the context of FE by C. albicans. Some guidelines recommend AMB as first-line therapy based on a limited experience with small case series, which represents a very low quality of evidence.

We found as a difficult point the fact that is hard finding scientific evidence to help physicians make clinical decisions, 
especially in therapeutic terms. We consider that compiling the available information beyond observational studies and case series can help us guide a better pharmacological approach to existing cases.

\section{CONCLUSION}

From our research, AMB seemed to be an important therapeutic option for C. albicans endocarditis, decreasing mortality and increasing the survival rate, and presenting a better response confirmed by laboratory and imaging exams.

\section{No financial support.}

No conflict of interest.

\section{Authors' roles \& responsibilities}

LSB Substantial contributions to the conception or design of the work; or the acquisition, analysis or interpretation of data for the work; drafting the work or revising it critically for important intellectual content; final approval of the version to be published

JAS

Substantial contributions to the conception or design of the work; or the acquisition, analysis or interpretation of data for the work; drafting the work or revising it critically for important intellectual content; final approval of the version to be published

MAOSV Substantial contributions to the conception or design of the work; or the acquisition, analysis or interpretation of data for the work; drafting the work or revising it critically for important intellectual content; final approval of the version to be published

SGL Substantial contributions to the conception or design of the work; or the acquisition, analysis or interpretation of data for the work; drafting the work or revising it critically for important intellectual content; final approval of the version to be published

AVCM Substantial contributions to the conception or design of the work; or the acquisition, analysis or interpretation of data for the work; drafting the work or revising it critically for important intellectual content; final approval of the version to be published

MBJ Substantial contributions to the conception or design of the work; or the acquisition, analysis or interpretation of data for the work; final approval of the version to be published

\section{REFERENCES}

1. Tacke D, Koehler P, Cornely OA. Fungal endocarditis. Curr Opin Infect Dis. 2013;26(6):501-7. doi:10.1097/QCO.0000000000000009.

2. Antinori S, Ferraris L, Orlando G, Tocalli L, Ricaboni D, Corbellino M, et al. Fungal endocarditis observed over an 8-year period and a review of the literature. Mycopathologia. 2014;178(1-2):37-51. doi:10.1007/ s11046-014-9754-4.

3. Öner $T$, Korun $O$, Çelebi A. Rare presentation of candida albicans: infective endocarditis and a pulmonary coin lesion. Cardiol Young. 2018;28(4):602-4. doi:10.1017/S1047951117002645.

4. Talarmin JP, Boutoille D, Tattevin P, Abgueguen P, Ansart S, Roblot F, et al. Candida endocarditis: role of new antifungal agents. Mycoses. 2009;52(1):60-6. doi:10.1111/j.1439-0507.2008.01533.x.

5. Guerriero M, Colasurdo F, Pollio AM. Huge candida albicans normal native tricuspid valve endocarditis. Autops Case Reports. 2018;8(2):e2018021. doi:10.4322/acr.2018.021.

6. Ellis ME, Al-Abdely H, Sandridge A, Greer W, Ventura W. Fungal endocarditis: evidence in the world literature, 1965-1995. Clin Infect Dis. 2001;32(1):50-62. doi:10.1086/317550.

7. Brandão M, Almeida J, Ferraz R, Santos L, Pinho P, Casanova J. Fungal prosthetic valve endocarditis with mycotic aneurysm : case report. Rev Port Cardiol. 2016;35(9):495.e1-4. doi:10.1016/j.repc.2015.11.028.

8. Colombo AL, Guimarães T. [Epidemiology of hematogenous infections due to Candida spp]. Rev Soc Bras Med Trop. 2003;36(5):599-607. doi:10.1590/s0037-86822003000500010. Portuguese.

9. Pai MP. Antifungal combinations against simulated candida albicans endocardial vegetations. Antimicrob Agents Chemother. 2009;53(6):2629-31. doi:10.1128/AAC.01026-08.

10. Hauser M, Hess J, Belohradsky BH. Treatment of candida albicans endocarditis: case report and a review. Infection. 2003;31(2):125-7. doi:10.1007/s15010-002-2187-x.

11. Victorio GB, Bourdon LMB, Benavides LG, Huerta-Olvera SG, Plascencia A, Villanueva J, et al. Antifungal activity of caspofungin in experimental infective endocarditis caused by candida albicans. Mem Inst Oswaldo Cruz. 2017;112(5):370-5. doi:10.1590/0074-02760160494.

12. Arnold CJ, Johnson M, Bayer AS, Bradley S, Giannitsioti E, Miró JM, et al. Candida infective endocarditis: an observational cohort study with a focus on therapy. Antimicrob Agents Chemother. 2015;59(4):2365-73. doi:10.1128/AAC.04867-14.

13. Stripeli F, Tsolia M, Trapali C, Papaevangelou V, Vlachos E, Pasparakis $D$, et al. Successful medical treatment of candida endocarditis with liposomal amphotericin B without surgical intervention. Eur J Pediatr. 2008;167(4):469-70. doi:10.1007/s00431-007-0498-8.

14. Noguchi M, Takai H, Eishi K, Atogami S. Prosthetic valve endocarditis due to candida albicans treated successfully with medical treatment alone. Jpn J Thorac Cardiovasc Surg. 2004;52(6):318-21. doi:10.1007/ s11748-004-0052-9.

15. Rivoisy C, Vena A, Schaeffer L, Charlier C, Fontanet A, Delahaye F, et al. Prosthetic valve candida spp. endocarditis: new insights into longterm prognosis-The ESCAPE study. Clin Infect Dis. 2018;66(6):825-32. doi:10.1093/cid/cix913.

16. Liberati A, Altman DG, Tetzlaff J, Mulrow C, Gøtzsche PC, loannidis JPA, et al. The PRISMA statement for reporting systematic reviews and metaanalyses of studies that evaluate health care interventions: explanation and elaboration. J Clin Epidemiol. 2009;62(10):e1-34. doi:10.1016/j. jclinepi.2009.06.006.

17. Manchikanti L, Benyamin RM, Helm S, Hirsch JA. Evidence-based medicine, systematic reviews, and guidelines in interventional pain management: part 3: systematic reviews and meta-analyses of randomized trials. Pain Physician. 2008;12(1):35-72.

18. Badiee P, Amirghofran AA, Nour MG, Shafa M, Nemati MH. Incidence and outcome of documented fungal endocarditis. Int Cardiovasc Res J. 2014;8(4):152-5.

19. Melgar GR, Nasser RM, Gordon SM, Lytle BW, Keys TF, Longworth DL. Fungal prosthetic valve endocarditis in 16 patients. An 11-year experience in a tertiary care hospital. Medicine (Baltimore). 1997;76(2):94-103. doi:10.1097/00005792-199703000-00002.

20. Flanagan PG, Barnes RA. Hazards of inadequate fluconazole dosage to treat deep-seated or systemic candida albicans infection. J Infect. 1997;35(3):295-7. doi:10.1016/s0163-4453(97)93270-9. 
21. Karatza AA, Dimitriou G, Marangos M, Christofidou M, Pavlou V, Giannakopoulos I, et al. Successful resolution of cardiac mycetomas by combined liposomal amphotericin B with fluconazole treatment in premature neonates. Eur J Pediatr. 2008;167(9):1021-3. doi:10.1007/ s00431-007-0634-5.

22. Hernández-Torres A, García-Vázquez E, Laso-Ortiz A, Herrero-Martínez JA, Gómez-Gómez J. [Candida sp endocarditis. Experience in a third-level hospital and review of the literature]. Rev Esp Quimioter. 2013;26(1):51-5. Spanish.

23. Kojic EM, Darouiche RO, Biofilms C. Candida infections of medical devices. Clin Microbiol Rev. 2004;17(2):255-67. doi:10.1128/cmr.17.2.255-267.2004.

24. Habib G, Lancellotti P, Antunes MJ, Bongiorni MG, Casalta JP, Del Zotti F, et al. 2015 ESC guidelines for the management of infective endocarditis. Rev Rom Cardiol. 2016;26: 343-405.

25. Azap OK, Ergönül Ö. Antifungal Stewardship. In: AMS Strategies. 2017. p. 147-63.

26. López J, Sevilla T, Vilacosta I, Sarriá C, Revilla A, Ortiz C, et al. Prognostic role of persistent positive blood cultures after initiation of antibiotic therapy in left-sided infective endocarditis. Eur Heart J. 2013;34(23):1749-54. doi:10.1093/eurheartj/ehs379.

27. Pappas PG, Kauffman CA, Andes DR, Clancy CJ, Marr KA, Ostrosky-
Zeichner $\mathrm{L}$, et al. Clinical practice guideline for the management of candidiasis: 2016 update by the infectious diseases society of America. Clin Infect Dis. 2015;62(4):e1-50. doi:10.1093/cid/civ933.

28. Baddour LM, Wilson WR, Bayer AS, Fowler VG Jr, Tleyjeh IM, Rybak MJ, et al. Infective endocarditis in adults: diagnosis, antimicrobial therapy, and management of complications: a scientific statement for healthcare professionals from the American heart association. Circulation. 2015;132(15):1435-86. Erratum in: Circulation. 2015;132(17):e215. Erratum in: Circulation. 2016;134(8):e113. Erratum in: Circulation. 2018;138(5):e78-9. doi:10.1161/CIR.0000000000000296.

29. Alkhouli M, Rihal CS, Zack CJ, Eleid MF, Maor E, Sarraf M, et al. Transcatheter and surgical management of mitral paravalvular leak: long-term outcomes. JACC Cardiovasc Interv. 2017;10(19):1946-56. doi:10.1016/j.jcin.2017.07.046.

30. Aydin U, Sen O, Kadirogullari E, Onan B, Yildirim A, Bakir I. Surgical transapical approach for prosthetic mitral paravalvular leak closure: early results. Artif Organs. 2017;41(3):253-61. doi:10.1111/aor.12757.

31. Lefort A, Chartier L, Sendid B, Wolff M, Mainardi JL, Podglajen I, et al. Diagnosis, management and outcome of candida endocarditis. Clin Microbiol Infect. 2012;18(4):E99-109. doi:10.1111/j.14690691.2012.03764.x. 